\title{
Other Sex: A Study on Problems of Transgender women of District Srinagar
}

\author{
Aijaz Ahmad Bund \\ PhD Scholar, Department of social work, University of Kashmir, India
}

\begin{abstract}
The rationale of this paper is to accentuate the problems of transgender women and to formulate a set of recommendations to address these problems. A transgender woman is a male to female transgender and a transgender is a person whose self-identity does not conform unambiguously to conventional notions of male or female gender (Oxford Dictionary). They face harassment from multi-dimensional sources, from parents, teachers, peers, society... and it includes each sphere of their lives. In Jammu and Kashmir there is no Transgender welfare Board therefore the problems of the third gender remain unattended. There is an immense need to address their problems in order to make them fully functional human beings by guaranteeing and safeguarding their rights. Present study is an empirical study in which the desired information (socio-economic profile) was extracted by using an interview schedule and the mental health was studied by using MINI (Mini Neuropsychiatric Interview) module A,C,E,G,H,I,L. Hundred respondents were selected through snowball technique. The purpose for using this sampling technique is that the transgender women in Kashmir doesn't live in communities as is typical of other states in India. The social recognition of transgender women is very low in Kashmir and so their visibility. Therefore the exact number of the transgender women in Jammu and Kashmir is not known. It can be concluded from the study that the intervention of the problems of transgender women need the individual, community and policy level approach.
\end{abstract}

Key words: Transgender women, abuse, problems, social, economic

\section{Introduction}

The term "transgender" is generally used to describe those who transgress social gender norms. Transgender is often used as an umbrella term to signify individuals who defy rigid, binary gender constructions and who expresses or present a breaking and blurring of culturally prevalent stereotypically gender roles. It includes pre-operative, post-operative and non- operative transsexual people who strongly identify with gender opposite to their biological sex (UNDP India Report, 2010). In Kashmir we have only non operative transgender women. We cannot talk of gender empowerment by socially excluding third gender. The empowerment of the socially ostracized sections of the society has to be gender, class and caste inclusive. The colossal problems of the transgender women demand a scientific study and proper intervention. The socio- economic problems like no property ownership, low economic status or monthly income, poor housing, lower education level, high physical, sexual and verbal abuse, no ownership of voter card; ration card, poor physical health status, less family support, hostile attitude of community etc and unsatisfactory psychological health are common problems in transgender women of Kashmir. For mainstreaming of gender and promotion of social justice every section of the society be it men, women or other gender has to be equally developed. Keeping in view the above discussion it is obligatory to explore the problems of the transgender women and the present study is forwarded in this direction.

\section{Review of literature}

Boyd, H. (2003) in her book "My Husband Betty: Love, Sex, and Life with a Cross-dresser" is a happily married woman whose husband enjoys sharing her wardrobe - and she has written the first book on transgendered men to focus on their relationships. Traditionally known as cross-dressers, transvestites, or drag queens, men like Helen's husband are a diverse lot who don't always conform to stereotype. Helen addresses every imaginable question concerning the probable and improbable reasons for behavior that still baffle not only "mental health professionals" but the practitioners themselves; the taxonomy of the transgendered and the distinct but overlapping societies of each group; coming out; bisexuality, and homophobia. The book features interviews with some very interesting people: a dominatrix and her cross-dressing husband; a cross-dressing Reiki master and his son; a woman who after dating one cross dresser wanted to date others and fell in love with a transsexual instead; and a woman whose husband promised her he was only a cross dresser who later realized that he was transsexual. Helen Boyd breaks new ground with an honest view into the lives of cross dressing men and the important people in their lives. Her perspective, as the spouse of a cross dresser, is unique among authors writing about this widely misunderstood community. The emotional honesty delivered in 
these pages results from her first hand experience in an honest and loving relationship that ultimately put her in touch with all aspects of the transgender community. This is no clinical study, but it does document some of the history and current theories of gender expression outside of mainstream society. It is a very frank, informative and intimate view of the human side of people often stigmatized or ridiculed in today's popular media. Men and women dealing with this issue will find ideas and real life examples that will assuredly provide insight into their own relationships. Even educators and psychological practitioners will find this a fascinating introduction to a subject that is often riddled with secrecy, bias and misinformation.

Guevara, L.A in the report "The Hidden Epidemic: Transgender Women in the Latin America and Asia" tries to draw our attention towards the vulnerability of transsexual women to HIV. According to UNAIDS, AIDS Epidemic update, 2007 the prevalence rate HIV for transsexual women in India is $42 \%$. The multicentre study from same year in Argentina puts the transgender prevalence rate of HIV at 35\%. The report further adds the statistical report regarding HIV and AIDS prevalence in transsexual women and puts various recommendations for strengthening organizations of transsexuals to divulge their problems.

James, T. Sears. (2007). in the book "lesbian and transgender issues in education programs, policies and practices" draws our attention towards the taunts that adolescent transgender in particular face. The words like faggot, queer, sissy etc are common comments passed to transgender. This name calling practice intends to harass a person. This book examines policies affecting LGBTQI youths within academic communities. Thus reflects upon their own experiences as youths in LGBTI community and addresses areas of law and society that impacted whether or not they had been in comfortable environments to learn. Authors also extend that children should be exposed to controversial topics, such as societal construct of gender and normalcy of homosexuality as early as at elementary level. Gay, lesbian, transgender issues in education also addresses legal aspects of problems in LGBTI Education. The book also covers the area of school sponsored programs addressing issues such as gay - straight alliance groups and LGBTI inclusive educational programs.

\section{Objective of study}

1: To make a scientific investigation of nature, dimensions, causes and implications of problems of transgender women of district Srinagar.

2: To develop a set of recommendations for the welfare of transsexual community.

\section{Methodology}

The present study is exclusively a quantitative study in which the socio economic profile of respondents was studied by using a schedule. The psychological health of the respondents was studied by using Mini International Neuropsychiatric Interview (M.I.N.I) English version 5.0.0, module A,C,E,G,H,I,L. Hundred respondents were selected through snowball technique. In snow ball technique, the researcher begins the research with few respondents who are known and available to him. Subsequently these respondents give other names who meet the criteria of research. This process is continued until adequate number of respondents is interviewed. The data was analyzed manually.

\section{Results of the study}

Out of 100 respondents, 36 respondents have migrated from rural areas to Srinagar. Out of the 36 respondents 9 migrated in search of job, two migrated for receiving education, 16 migrated due to harassment by friends and relatives and nine were disowned by their family members.

The nature of the harassment included verbal abuse, assault; bullying, sexual violence etc. the impact was social restrictions which resulted in immense psychological disturbances. The outcome was migration, no attendance in social participation, avoiding social institutions like schools, marriages, festivals, and places of worship. The nature of migration is permanent for 19 respondents and 17 want to return to their place of birth. Ten percent of respondents are of the age group 15-20 years. Four percent are of the age group 20-25. Sixteen percent are of the age group 25 to 30 years. Eighteen percent are of the age group 30- 35 years. Eleven percent is of the age group 35-40 years. Fifteen percent of the respondent population is of the age group 40-45 years. Fifteen percent respondents are of age group 45-50 years. Eight percent of the respondents are of age group 5055 years. And three percent respondents are above 55 years. Majority of respondents are youth. Therefore their potential being youth needs to be harnessed.

Thirty percent of respondents never attended school. Fifty five percent of the respondents completed the primary level of school education. Ten percent completed high school education. Four percent of respondents completed $12^{\text {th }}$ grade. One percent respondents completed vocational training course. Zero percent respondents completed tertiary level of education.

Forty-five percent of the respondents faced harassment at school level. Twelve percent of respondents were physically harassed. Thirteen percent were sexually harassed. Sixty percent were verbally abused. Fifteen percent says that they were physically and sexually harassed. Twelve percent of respondents said that 
they were harassed by their teachers. Sixty percent respondents were harassed by the students or the classmates. Fifteen percent were harassed by the students as well as teachers. Thirteen percent respondents were harassed by the non teaching staff of the school. This is the possible reason of not continuing studies.

Forty five percent of the respondents are unemployed. Eighteen percent of the respondents are into match making. Twelve percent dance at marriage parties. Three percent respondents are working as sex workers. Twenty percent of the respondents work as domestic helpers. Two percent respondents are into manual labor. Zero percent of respondents are into Government or Private Jobs. All the respondents claim that they face problems in whatever work they are doing. The respondents working as match makers say that they are often mistreated by the parties of marriage. The respondents who dance at marriage parties claim that they are sexually and verbally abused. The respondents who are in the sex work say that they are often mistreated by the clients and police has a hostile attitude towards them. Domestic worker respondents claim exploitation in terms of low wages and more work load. The respondents who work as manual labors also claimed harassment by fellow workers or the masters.

Two percent of the respondents made career choice below the age of 15 years. Forty percent of respondents made career choice between the age group of 15-20 years. Fifteen percent of respondents made their career choice between $20-25$ years. Thirty percent of the respondents made the career choice between the ages $25-30$ years. Twelve percent of the respondents made career choice at the age limit of 30-35 years. One percent of the respondents made career choice above 35 years. Twelve percent of the respondents are satisfied with their career choice. Thirteen percent of respondents are somewhat satisfied with their career choice. Twenty five percent respondents are unsatisfied with their career choice. Fifty percent of the respondents are extremely unsatisfied with their career choice. The unsatisfactory career choice may be partly attributed to the nature of occupation and partly to the harassment that they face at their respective work places.

Fifty percent of the respondents have the income below Rs 1000 . The monthly income of sixteen percent respondents is between Rs 1000-30000. Thirteen percent respondents have a monthly income which ranges between Rs 3000-6000. Six percent of respondent's monthly income is between $6000-9000$. Eight percent respondents have a monthly income ranging between Rs 9000-12000. Seven percent respondents have the monthly income of more than Rs 12000.

Thirty eight percent of respondents are living alone in the rented houses. Two percent of respondents live with their partners. Thirty percent of respondents live with other transgender. Fifteen percent respondents are living with their parents or family. Fifteen percent of respondents live alone in their own shelters.

Only fifteen percent of the respondents have their own property. For the rest of the respondents the property right has either been denied or not assigned yet. For the fifteen percent respondents the property share has not been given. Sixty percent respondents claim that their property rights were denied.

Only 8 percent of the respondents have a voter card and zero percent respondents have casted a vote, and fifteen percent have ration card. Two percent respondents have a bank account. The reason for not having voter card, ration card or the bank account may be attributed to the low economic status, limited education and lack of awareness.

Hundred percent of the respondents claim that they face discrimination on social grounds. The discrimination varies from one situation to other.

Eight percent of the respondents rate their heath as extremely bad. Thirteen percent respondents rate their heath as bad. Twenty percent respondents rate their health as in between good and bad. Forty five percent of respondents rate their heath as good. And fourteen percent respondents rate their heath as very good. The common heath issues as revealed by the respondents were hypertension, diabetes, Urinary Tract Infection, GIT ailments, joint pain, Respiratory infections, skin problems etc.

Only 13 percent respondents have some knowledge of Sexually Transmitted Diseases and Condom. No respondent has ever gone for screening of Sexually Transmitted Diseases.

Fifty percent respondents acknowledged to have excluded themselves form social participations. The main reason for exclusion can be attributed to the fear of ridicule and harassment. Twelve percent respondents have excluded themselves from livelihood and employment opportunities. Forty five respondents have excluded themselves from decision making processes. Three percent respondents have restricted access from collectivization. Forty percent respondents admit to have restricted their rights of citizenship.

Hundred percent of respondents feel politically alienated. They feel that they have no say in the political system of Kashmir. They find no place in the mainstream or the separatist politics.

All the respondents claim that when the family and the community came to know about their gender identity their approach was not supportive. The family and community were never supportive or favorable for them.

All the respondents are of the view that the hetero normative role is always imposed on them by their family members, peers or other people. They feel problems in adapting to the social pressure. They also think 
that their gender identity has a negative impact on them and their families as society doesn't consider them as dignified individuals.

All the respondents are of the opinion that there should be a community support group and Transgender Welfare Board so that their issues are addressed and their voice heard.

No respondent is a part of any social welfare scheme. They are not even aware of such programs and schemes.

Twenty percent of the respondents illustrate the symptoms of Major Depressive Episode; fourteen percent respondents show the symptoms of suicidability. Eighteen percent respondents demonstrate the symptoms of Panic disorder. Eighteen percent of the respondents show the symptoms of the Social Anxiety Disorder. Twelve percent of the respondents show OCD symptoms. Forty eight percent of the respondents illustrate the symptoms of PTSD whereas zero percent of the respondents show symptoms of Psychotic Disorders. The mental health of the respondents depicts low standard. And it is advisable to deal the problems professionally.

\section{Recommendations}

1. To sensitize the people with regard to the identity of transgender.

2. Along with vocational and training programs there should be more livelihood avenues for transgender.

3. Formal and non-formal educational programs should be introduced at policy level.

4. Government should formulate such programs which will ensure the social, economic and political rehabilitation of transgender.

5. Government should introduce reservations in educational intuitions and Government jobs for such people.

6. There should be a Transgender Welfare Board in $\mathrm{J} \& \mathrm{~K}$

7. There should be a counseling center for sexual minorities in every district of $J \& K$

8. All the laws should be applicable to the transgender like other people. They should be treated equally, courteously and without any intolerance.

9. Shelter homes should be made accessible for such transgender women who are facing violence.

10. Support of civil society organizations to advocate their cause and efforts e.g. ownership of land, shelter, recognition of their rights to vote as citizens and formation of associations etc.

\section{Conclusion}

Preamble to the constitution mandates justice-social, economic, and political equality of status. Thus the first and the foremost right transgender are deserving of is the Right to Equality under Article 14. Article 15 speaks about the prohibition of discrimination on the ground of religion, caste, sex or place of birth. Article 21, ensures right to privacy and personal dignity to all the citizens. The constitution provides for the fundamental rights to the equality and tolerates no discrimination on the grounds of sex, caste, creed or religion. The constitution also guarantees political rights and other benefits to every citizen. Despite such laws in the constitution of India, the other sex (transgender) continues to be ostracized.

Transgender people are called "laanch" in Kashmir which in itself is stigmatization and a ground of discrimination. They face unfairness in every aspect of life be it employment, legal recognition, access to social resources including decent life standard and education. For all of them the struggle usually starts from an early phase. The non conformity, to their prescribed gender roles makes them vulnerable and often leads to verbal and corporeal abuse at the hands of their parents, siblings and other family members. The intimidating environment even prevails at schools and other educational institutions which almost certainly force them to leave studies in order to avoid the mocking and harassment which leads to the mental trauma.

Transgender women of Kashmir face multiform of oppression. It is due to the discrimination they face at every level of life, that they don't have the confidence to take part in the social and political decision making. Their low educational levels make them ineligible for white collar jobs. The odd jobs fetches out paltry income hence making them more vulnerable. More than 60 percent of the respondents have low economic status. The harassment at family, school and community forces them to move to the other places. The nature of the harassment includes verbal, physical and sexual abuse which has serious impact on the mental health as well. The mental health issues include Post Traumatic Stress Disorder (PTSD), Obsessive Compulsive Disorder (OCD), Major Depressive Episode (MDE), suicidal tendencies and Panic Disorders.

Having least knowledge about the condom and Sexually Transmitted Diseases (STD's) makes them more vulnerable to catch venereal diseases. In a democratic country like India Transgender women of Kashmir has never casted a vote or has no access to the social and political rights. They are not the part of any welfare scheme.

Keeping in view the above findings it can be concluded that there is an immense need to intervene at individual, community and policy level to safeguard the rights of transgender. 


\section{References}

[1] Boyd,H.(2003). My Husband Betty: Love, Sex, \& Life with a Cross Dresser. Seal Press: Berkeley California

[2] Bornstein, K. (1995). Gender Outlaw: On Men, Women and the Rest of Us. Vintage Publications

[3] James, T. Sears (2007). Lesbian and Transgender Issues in Education Programs, Policies and Practices.

[4] King,M.(2010). Filth. Loveyoudivine Alterotica Publications

[5] Serano,J. (2007). Whipping Girl: A Transsexual woman on Sexism and Scapgoating of Feminity. Seal Press: Berkeley California

[6] Stryker,S. (2008). Transgender History. Seal Press: Berkeley California

[7] Sycamora, B.M.(2006). No Body passes: Rejecting the Rules of Gender and Conformity. Seal Press: Berkeley California

[8] Valerio,W.M.(2006). The Testosterone Files: My Hormonal and Social Transformation from Female to Male. Seal Press: Berkeley California

Author's Profile

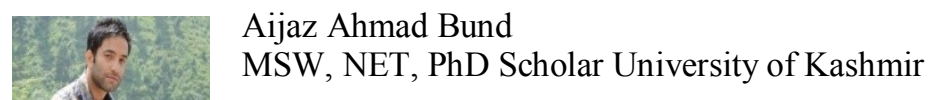

